\title{
PERANCANGAN DAN ANALISA PC CLONING MENGGUNAKAN WINDOWS MULTIPOINT SERVER 2012 PADA UNIT PELAKSANA TEKNIS PELAYANAN PEMBELAJARAN (UPT PP) UNIVERSITAS LAMPUNG
}

\author{
Martias Hasan ${ }^{1}$, Ageng Sadnowo $\mathbf{R}^{2}$, Gigih Fordanama ${ }^{3}$. \\ 1,2,3 Jurusan Teknik Elektro Universitas Universitas Lampung \\ Jl. Prof. Sumantri Brojonegoro No.1 Bandar Lampung 35145 \\ 'martias.hasan@yahoo.com, ${ }^{2}$ ageng@unila.ac.id, ${ }^{3}$ gigih@unila.ac.id
}

\begin{abstract}
Abstrak- UPT PP merupakan lembaga pendidikan yang bertugas menangani pelatihan pembelajaran bagi civitas akademik. UPT PP memiliki tanggung jawab untuk melayani kebutuhan masyarakat dalam bidang akademik. UPT PP telah memiliki laboratorium komputer untuk menunjang kegiatan pelatihan multimedia. tetapi jumlah komputer belum mencukupi dibandingkan dengan peserta yang mengikuti pelatihan. Penambahan perangkat komputer membutuhkan biaya yang besar.

PC Cloning adalah efisiensi penggunaan perangkat lunak dan perangkat keras memungkinkan komputer dapat digunakan oleh lebih dari 1 user. PC Cloning dapat menghemat konsumsi listrik karena konsumsi 4 unit komputer dapat dihemat menjadi 1 unit komputer. PC Cloning menghemat dan mengurangi pembelian perangkat komputer. PC Cloning harus dilakukan pengujian untuk membuktikan performa CPU dan penghematan konsumsi listrik. Pengujian konsumsi listrik dilakukan dengan cara membandingkan konsumsi listrik PC tanpa Cloning dan PC Cloning dalam mode stanby dan mode aktif.
\end{abstract}

Kata Kunci : PC Cloning, Konsumsi Litrik, Pengujian, Performa CPU.

Abstract- UPT PP is the institution in charge for the training of academic learning for Civitas. UPT PP has a responsibility to serve the needs of the academic community. UPT PP has a computer lab to support multimedia training activities. but insufficient number of computers compared to participants following the training. The addition of computer tools requires huge cost

PC Cloning is the efficient use of software and hardware enables a computer can be used by more than one user. Cloning PC can save power consumption due to consumption of 4 units of computers can be saved into one unit of a computer. PC Cloning save and reduce purchasing computer equipment. PC Cloning should be tested to prove the performance CPU and reliability of electricity consumption savings. Electricity consumption testing was done by comparing the power consumption of a PC without Cloning and PC Cloning in Standby mode and active mode.

Keywords: PC Cloning, power consumption, testing, performance CPU.

\section{Pendahuluan}

Unit Pelaksana Teknis Pelayanan Pembelajaran (UPT PP) merupakan salah satu lembaga pendidikan yang menangani pelatihan pembelajaran bagi civitas akademik yang memiliki tanggung jawab untuk melayani kebutuhan masyarakat dalam mendapatkan kursus-kursus soft skill yang diberikan dalam rangka meningkatkan kualitas pendidikan dalam masyarakat. Untuk menunjang hal tersebut UPT PP telah memiliki sebuah Laboratorium Komputer yang digunakan sebagai tempat pelatihan civitas akademik terutama dibidang multimedia pembelajaran. Tetapi sayangnya jumlah unit komputer yang tersedia pada laboratorium komputer UPT PP belum mencukupi, dibandingkan dengan jumlah peserta yang mengikuti pelatihan multimedia. Sedangkan untuk menambah komputer baru memerlukan waktu yang lama serta biaya yang tidak sedikit. Atas dasar masalah tersebut penulis ingin merancang sebuah perangkat komputer yang dapat digunakan oleh lebih satu orang (multiuser).

Pada awalnya Personal Computer (PC) dikonsepkan hanya untuk satu pengguna saja atau sering disebut one user, one komputer. Tetapi seiring perkembangan teknologi dibidang komputer teknik multiuser tersebut bisa diterapkan. Teknik multiuser ini biasa disebut dengan PC Cloning. 


\section{Tinjauan Pustaka}

\subsection{Pengenalan PC Cloning}

PC Cloning merupakan sebuah teknologi komputer masa kini yang memungkinkan sebuah Central Processing Unit (CPU) dapat digunakan untuk dioperasikan oleh lebih dari satu pemakai sekaligus. Biasanya sebuah CPU hanya dapat dipakai oleh satu orang pemakai saja. Dengan teknologi PC Cloning ini, paradigma $1 \mathrm{CPU}$ untuk 1 pemakai telah berubah, sehingga $1 \mathrm{CPU}$ sekarang dapat digunakan, hingga 20 pemakai sekaligus.

PC Cloning Merupakan Suatu sistem yang diterapkan pada jaringan komputer, digunakan untukmentransfer kemampuan hardware server keseluruh client yang terkoneksi.[1]

PC Cloning bekerja dengan memanfaatkan secara maksimal sumber daya yang dimiliki sebuah CPU, antara lain: prosessor, memori, dan hardisk. Pada prinsipnya, tidak semua sumber daya CPU digunakan secara maksimal saat seorang pemakai menggunakan komputer.[2]

\subsubsection{Keunggulan penerapan PC Cloning} Teknologi PC Cloning memiliki beberapa keunggulan diantaranya :

1. Menghemat kebutuhan software.

2. Menghemat kebutuhan hardware.

3. Menghemat pemakaian listrik.

4. Menghemat biaya investasi.

5. Kemudahan perawatan PC. [5]

\subsubsection{Kelemahan penerapan PC Cloning}

Penerapan PC Cloning bukan tanpa kekurangan, kekurangan yang terdapat pada PC Cloning adalah, jika pengguna yang terhubung pada Server terlalu banyak, akan menyebabkan kinerja Server tersebut menurun. Oleh karena itu perlu disesuaikan antara jumlah client dengan spesifikasi Server.

\subsection{Kinerja Komputer}

Kinerja komputer dicirikan oleh banyaknya jumlah pekerjaan yang dapat dilakukan oleh sistem komputer dibandingkan dengan waktu dan sumber daya yang digunakan. Tergantung pada batasannya, kinerja komputer yang baik dapat di ukur berdasarkan salah satu hal berikut:

1. Respon waktu yang cepat untuk menjalankan aplikasi perkantoran dan aplikasi multimedia.
2. Rendahnya pemanfaatan sumber daya komputasi (Persentase penggunaan prosecor pada saat menjalankan aplikasi perkantoran dan multimedia) .

3. High availability dari sistem komputasi atau aplikasi.

4. Cepat atau berbarengan antara data kompresi dan dekompresi.

5. Bandwidth yang tinggi / transmisi data waktu yang pendek.[2]

\subsection{Windows Multipoint Server 2012}

Windows Multipoint Server 2012 adalah versi ketiga dari produk Windows Server dan merupakan varian dari Windows Server 2012. Dirancang untuk memungkinkan beberapa pengguna untuk secara bersamaan berbagi satu komputer.

Pengguna memiliki pengalaman mereka sendiri independen dan akrab komputasi Windows. Windows Multipoint Server 2012 memungkinkan lebih banyak pengguna untuk mengakses teknologi dengan total biaya kepemilikan yang lebih rendah.

Windows Multipoint Server 2012 memberikan pengguna desktop secara individu dengan tampilan Windows 8. Ini juga menawarkan Multipoint antarmuka pengguna yang sederhana Manajer administrator sistem dapat digunakan untuk visibilitas dan kontrol atas Server beberapa Multipoint.[3]

\subsubsection{Kelebihan Windows Multipoint Server 2012}

Kelebihan Windows Multipoint Server adalah sebagai berikut :

1. Dapat Mengelola beberapa Server Multipoint di laboratorium komputer, ruang kelas, pusat pelatihan, atau lingkungan usaha kecil.

2. Instal program hanya sekali pada sisi Server, dan dapat diakses di setiap stasiun.

3. Berikan setiap pengguna pengalaman komputasi pribadi dan folder pribadi tanpa perlu komputer yang terpisah untuk setiap orang.

4. Memonitor tampilan thumbnail dari aktivitas desktop setiap pengguna .

5. Dapat memblokir layar dengan pesan disesuaikan yang dilakukan dari sisi Server.

6. Membatasi kelompok untuk hanya 
mengakses satu atau lebih website

Server.

7. Proyek layar ke layar lain untuk

8. menunjukkan tugas tertentu.

\subsubsection{Varian Windows Multipoint Server} 2012.

Windows Multipoint Server 2012 terbagi atas 2 jenis produk yaitu versi standar dan versi premium.

1. Versi Standar

2. Premium.[5]

\subsubsection{Kebutuhan Hardware Windows Multipoint Server 2012}

Kebutuhan hardware minimal yang dibutuhkan untuk menjalankan sistem operasi Windows Multipoint Server 2012 dijelaskan dalam tabel di bawah ini :

Tabel 2.1. Spesifikasi hardware yang dibutuhkan untuk menjalankan Windows Multipoint

\begin{tabular}{|c|c|}
\hline Komponen & Kebutuhan \\
\hline Prosesor & Minimum $1.4 \mathrm{GHz} 64$ bit processor \\
\hline Memori & Minimum $1 \mathrm{GHz}$ \\
\hline Ketersediaan ruang harddisk & Minimum $32 \mathrm{~GB}$ \\
\hline Drive & DVD-ROM drive \\
\hline Perangkat munitor dan Peripheral & $\begin{array}{l}\text { Super VGA }(800 \times 600) \text { atau lebih } \\
\text { tinggi, keyboard serta mouse }\end{array}$ \\
\hline
\end{tabular}

\section{Metodologi Penelitian}

Berikut adalah langkah yang dilakukan pada penelitian ini:

\subsection{Tahap Analisa Kebutuhan Sistem}

Tahap analisa sistem yang digunakan untuk mendefinisikan dan menggambarkan kebutuhan pemakai secara detil, waktu spesifik dan hambatan biaya. Tugas utama analisa kebutuhan sistem adalah :

1. Menetapkan ruang lingkup sistem

2. Mengumpulkan fakta studi

3. Menganalisis fakta studi

\subsection{Kebutuhan Target}

Pada prinsipnya semua kegiatan komputer yang berada pada sisi user pada sistem Cloning semuanya dilakukakan pada sisi Server. Sehingga sistem Cloning sangat membantu memanfaatkan komputer yang hanya memiliki satu pengguna, menjadi komputer yang dapat dipergunakan oleh dua orang atau lebih. Adapun analisa kebutuhan target adalah sebagai berikut :

Dilihat dari sistem kerjanya, teknik PC Cloning ini baik untuk digunakan oleh dua user atau lebih yaitu :

1. PC Cloning untuk kebutuhan rental

2. PC Cloning untuk kebutuhan pendidikan baik sekolah maupun kampus

3. PC Cloning untuk kebutuhan kantor

\subsection{Persyaratan Instalasi}

Dalam persyaratan instalasi terbagi atas dua yaitu:

1. Persyaratan Software.

2. Persyaratan Hardware.

\subsection{Arsitektur PC Cloning}

Cara kerja virtual Desktop pada Windows Multipoint Server 2012 yaitu dengan cara memanfaatkan kelebihan daya dari PC dan mengubahnya menjadi Server yang menjalankan Perangkat Akses untuk menyambungkan komputer host ke stasiun individu, yang memungkinkan banyak orang untuk berbagi komputer yang sama sambil tetap merasakan pengalaman komputasi yang independen.

Dalam Windows Multipoint Server 2012 terdapat tiga cara untuk menyambungkan Virtual Desktop yaitu:

1. Sambungan Langsung (dengan PCIe atau kartu VGA )

2. Sambungan USB (perangkat akses tersambung ke komputer user melalui kabel USB),

3. Sambungan LAN (PC pengguna akhir tersambung melalui thin client kedalam jaringan, bukan tersambung secara fisik ke komputer user).

Pada penelitian ini cara penyambungan Virtual Desktop yang dipergunakan adalah cara yang pertama dengan sambungan langsung yaitu melalui Port PCIe atau Kartu VGA yang di hubungkan Ke LCD kesetiap user dan perangkat akses (USB HUB) yang tersambung ke setiap komputer user melalui kabel USB sebagai Port perangkat Mouse dan Keyboard.[4] 


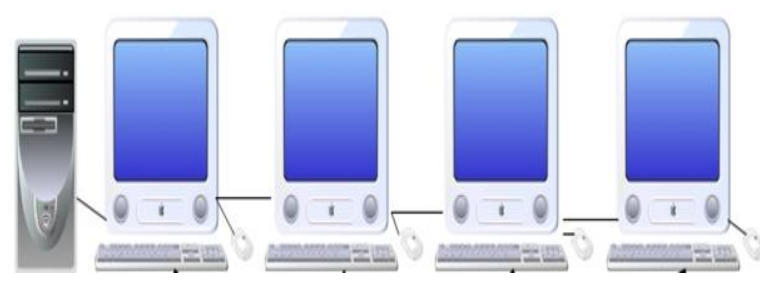

Gambar 3.1. Arsitektur PC Cloning.

\subsection{Perancangan}

Setelah menganalisis software dan hardware yang dibutuhkan dalam membangun PC Cloning maka langkah berikutnya yaitu melakukan perancangan berdasarkan analisa kebutuhan, serta instalasi perangkat lunak perangkat lunak. Perangkat lunak yang diunakan adalah Windows Multipoint Server (WMS) 2012. kemudian dilanjutkan dengan pengujian untuk membuktikan bahwa software dan hardware dapat berjalan dengan baik berdasarkan kondisi yang telah dibuat dengan acuan batasan masalah yang tertera yaitu pemakaian processor sebesar $80 \%$, Sehingga didapatkan user yang ideal yang dapat ditangani oleh PC Cloning sesuai dengan pesifikasi hardware yang digunakan dalam penelitian ini.

1. Perancangan Perangkat Keras

Tahap perancangan perangkat keras dimulai dari perakitan komputer agar mampu menjalankan dengan baik system operasi Windows Multipoint server 2012, langkah yang pertama yaitu dilakukan pemasangan VGA Card yang digunakan sebagai tampilan desktop setiap user. Kemudian mengecek apakah VGA Card yang dipasang sudah benar atau tidak dengan cara menghidupkan komputer dan masuk ke menu bios untuk mengaktifkan dual VGA hal ini dilakukan agar VGA Card tersebut dapat terbaca oleh sistem komputer.

Tahap perancangan dapat dijelaskan pada gambar berikut.

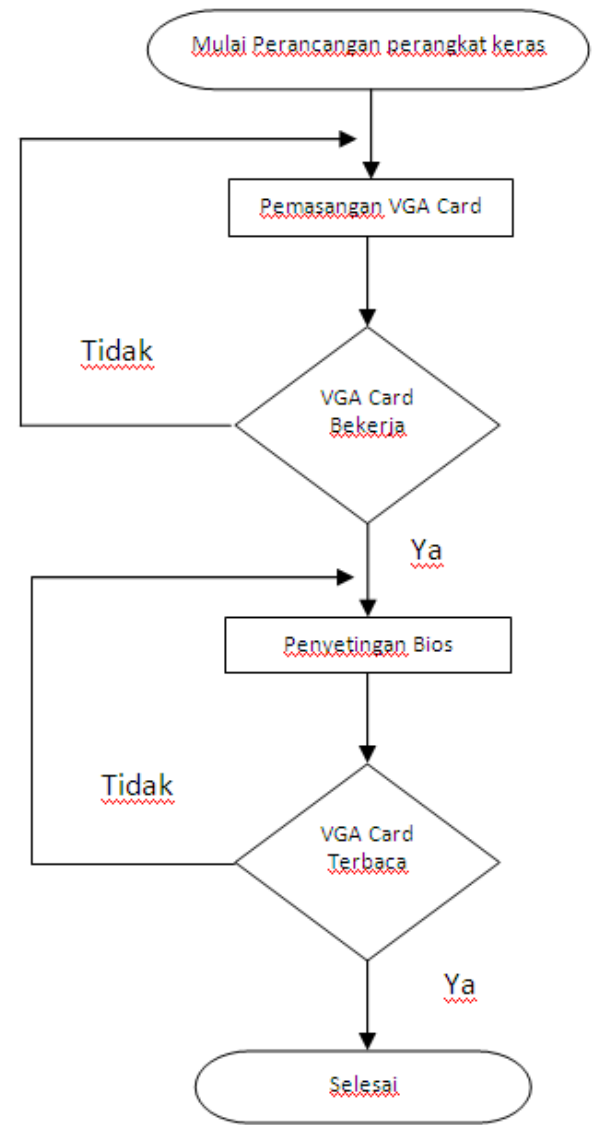

Gambar 3.2. Diagram Alir Perancangan Perangkat Keras.

\section{Penginstalan}

Tahapan penginstalan dimulai dengan penginstalan OS WMS 2012 pada komputer. Setelah OS berhasil di instal langkah selanjutnya adalah instalasi Driver. Penginstalan driver dilakukan agar perangkat komputer dapat bekerja terutama perangkat VGA yang digunakan dalam multipoint $u$ ser. Setelah instalasi driver selesai langkah selanjutnya adalah pembuatan user dalam OS WMS 2012. Pada tahapan ini kita akan membuat jumlah user yang akan digunakan dalam menjalankan berbagai aktifitas pada WMS 2012. Pada Penelitian ini user yang dibuat adalah sebanyak 5 buah. Langkah selanjutnya penginstalan aplikasi yang digunakan dalam pengujian PC Cloning yang berupa aplikasi kantor, aplikasi multimedia dan aplikasi grafis.

Tahap penginstalan dapat dijelaskan pada gambar berikut. 


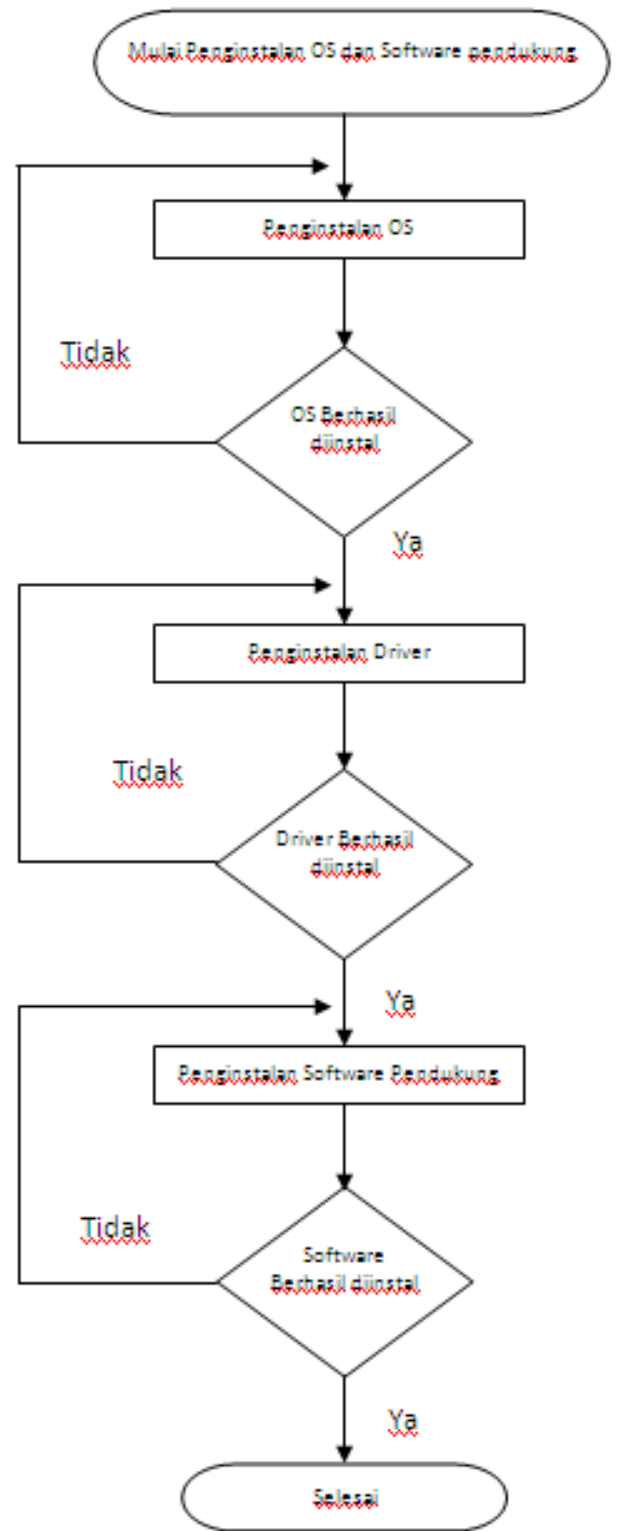

Gambar 3.3. Diagram Alir Penginstalan OS dan Software Pendukung.

\subsection{Pengujian dan Pembahasan}

Pada tahapan ini akan dilakukan analisa hasil dan pembahasan dari sistem yang telah dibangun. Analisa yang dilakukan diperoleh dari data yang telah didapat dari pengujian PC Cloning. Pengujian itu meliputi pengujian pemakaian listrik dan pengujian performa dari PC Cloning yang telah dibuat.

1. Pengujian pemakaian listrik.

Pengujian pemakaian listrik dilakukan dengan mengukur pemakaian listrik komputer tanpa PC Cloning dan komputer PC Cloning dengan menggunakan Wanf Multifunctional Mini Ammeter dalam mode stanby dan aktif. Pada mode Stanby pengujian dilakukan dengan mengukur konsumsi listrik pada komputer tanpa PC Cloning sampai dengan 4 user (1 komputer untuk setiap usernya) dan tidak menjalankan aplikasi. Pada mode aktif pengukuran konsumsi listrik dilakukan dengan menjalankan aplikasi baik aplikasi kantor, aplikasi multimedia dan aplikasi grafis.

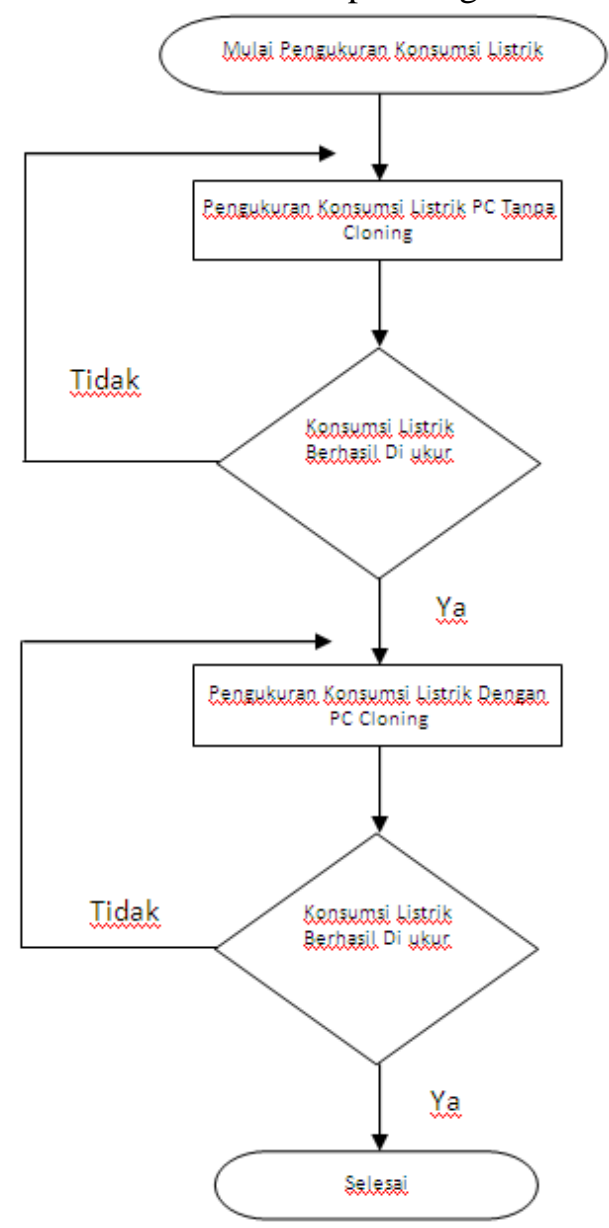

Gambar 3.4. Diagram Alir Pengukuran Konsumsi Listrik.

2. Pengujian Performa PC Cloning.

Dalam pengukuran performa PC Cloning dilakukan dengan cara mengukur kemampuan komputer dalam menjalankan aplikasi yang terdiri dari tiga pengelompokan yaitu aplikasi kantor, aplikasi multimedia dan aplikias grafis dan dilihat kinerjanya menggunakan aplikasi task manager, serta terbagi menjadi 2 mode pengaplikasian yaitu mode stanby dan mode aktif. Dari hasil uji coba yang akan dilakukan terhadap PC Cloning dalam menjalankan aplikasi aplikasi kantor, aplikasi multimedia serta aplikasi grafis maka dapat dilihat apakah alat telah berjalan dengan baik atau tidak. Sistem 
PC Cloning yang dikatakan baik apabila sistem tersebut dapat menjalankan aplikasi dengan baik dengan penggunaan CPU dibawah $80 \%$. Serta didapat pemakain jumlah user yang ideal sesuai dengan spesikasi komputer Server yang digunakan. Tahap pengujian performa dapat dijelaskan pada gambar berikut.

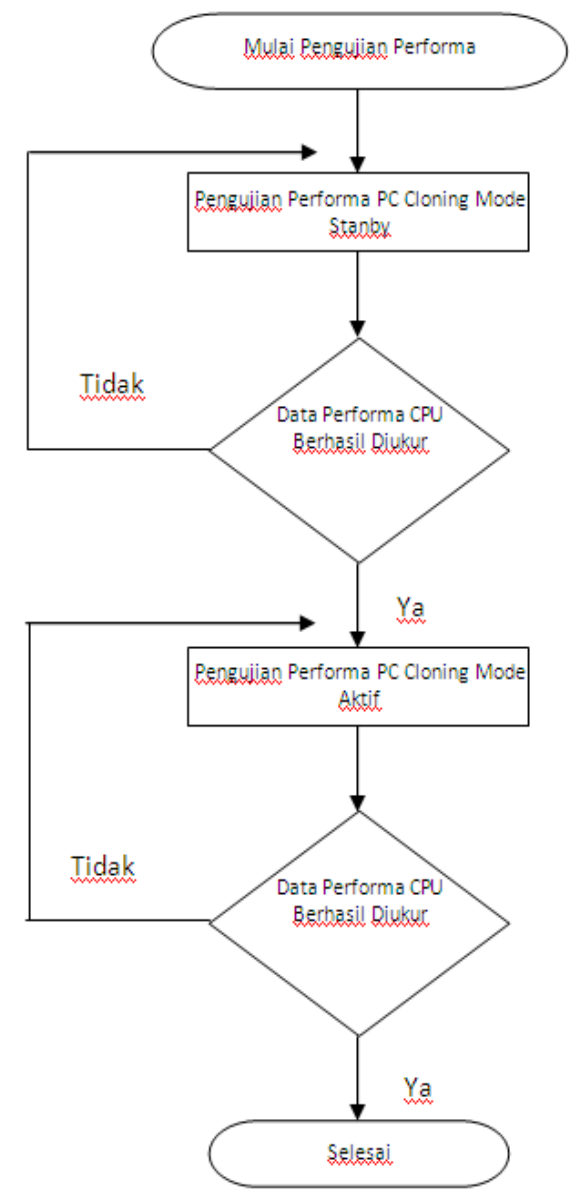

Gambar 3.5. Diagram Alir Performa PC Cloning.

\section{Hasil Dan Pembahasan}

\subsection{Hasil Penelitian}

Hasil penelitian ini terdiri atas dua hasil pengujian, pertama konsumsi listrik antara komputer tanpa PC Cloning dengan Komputer yang telah menggunakan PC Cloning, kedua hasil pengujian performa komputer yang telah menggunakan PC Cloning dalam dua mode pengaplikasian yaitu mode stanby dan mode aktif

\section{Konsumsi Listrik}

a. Konsumsi Listrik pada komputer dalam Mode Stanby.

Tabel 4.1. Konsumsi Listrik Pada Komputer dalam Mode Stanby.

\begin{tabular}{|l|l|l|c|c|}
\hline \multirow{2}{*}{ NO } & \multirow{2}{*}{ Jumlah User } & \multirow{2}{*}{ Jumlah Monitor } & \multicolumn{2}{|c|}{ Konsumsi daya (Watt) } \\
\cline { 4 - 5 } & & & Tanpa PC Cloning (x) & PC Cloning (y) \\
\hline 1 & 1 user & 1 unit & 64 & 86 \\
\hline 2 & 2 user & 2 unit & 114 & 100 \\
\hline 3 & 3 user & 3 unit & 175 & 120 \\
\hline 4 & 4 user & 4 unit & 243 & 137 \\
\hline
\end{tabular}

b. Konsumsi Listrik pada komputer dalam Mode Aktif

Tabel 4.2. Konsumsi Listrik Pada Komputer dalam Mode Aktif.

\begin{tabular}{|l|l|l|c|c|}
\hline \multirow{2}{*}{ NO } & \multirow{2}{*}{ Jumlah User } & \multirow{2}{*}{ Jumlah Monitor } & \multicolumn{2}{|c|}{ Konsumsi daya (Watt) } \\
\cline { 4 - 5 } & & & Tanpa PC Cloning (x) & PC Cloning (y) \\
\hline 1 & 1 user & 1 unit & 90 & 95 \\
\hline 2 & 2 user & 2 unit & 162 & 119 \\
\hline 3 & 3 user & 3 unit & 202 & 144 \\
\hline 4 & 4 user & 4 unit & 255 & 172 \\
\hline
\end{tabular}

c. Persentase Efisiensi Konsumsi Listrik Setelah mendapat data pengukuran konsumsi daya terpakai maka dapat di cari persentase koefisien konsumsi listrik dengan rumus berikut :

Persentase konsumsi

listrik $=\frac{x-y}{x} \cdot 100 \%$

Maka didapat data sebagai pada tabel berikut :

Tabel 4.3. Persentase Efisiensi Konsumsi Listrik Mode Stanby dan Mode Aktif.

\begin{tabular}{|l|l|l|c|c|}
\hline \multirow{2}{*}{ NO } & \multirow{2}{*}{ Jumlah User } & \multirow{2}{*}{ Jumlah Monitor } & \multicolumn{2}{|c|}{ Persentase Efisiensi Konsumsi Listrik } \\
\cline { 4 - 5 } & & & Mode Stanby (\%) & Mode Aktif (\%) \\
\hline 1 & 1 user & 1 unit & $-34,3$ & $-5,5$ \\
\hline 2 & 2 user & 2 unit & 12,2 & 26,5 \\
\hline 3 & 3 user & 3 unit & 32,5 & 28,7 \\
\hline 4 & 4 user & 4 unit & 43,6 & 32,5 \\
\hline
\end{tabular}




\section{Performa PC Cloning}

a. Aplikasi Kantor

Microsoft Office Word 2007.

Tabel 4.4. Kinerja CPU dan RAM Pada PC Cloning Menjalankan Aplikasi Microsoft Office Word 2007.

\begin{tabular}{|l|c|l|c|c|c|c|}
\hline \multirow{2}{*}{ No } & \multirow{2}{*}{$\begin{array}{c}\text { Jumlah } \\
\text { User }\end{array}$} & \multirow{2}{*}{ Monitor } & \multicolumn{2}{|c|}{ Kinerja CPU/ Processor (\%) } & \multicolumn{2}{c|}{ Kinerja RAM/Memori (\%) } \\
\cline { 5 - 8 } & & & Mode Stanby & Mode Aktif & Mode Stanby & Mode Aktif \\
\hline 1 & 1 user & 1 unit & 1 & 2 & 46 & 46 \\
\hline 2 & 2 user & 2 unit & 2 & 2 & 46 & 46 \\
\hline 3 & 3 user & 3 unit & 2 & 10 & 49 & 49 \\
\hline 4 & 4 user & 4 unit & 2 & 7 & 49 & 49 \\
\hline
\end{tabular}

b. Aplikasi grafis.

Mondo Marble

Tabel 4.5. Kinerja CPU dan RAM PC Cloning Menjalankan Aplikasi Mondo Marble.

\begin{tabular}{|c|l|l|c|c|}
\hline NO & Jumlah $u$ ser & $\begin{array}{c}\text { Jumlah } \\
\text { Monitor }\end{array}$ & $\begin{array}{c}\text { Kinerja CPU/ } \\
\text { Processor (\%) }\end{array}$ & $\begin{array}{c}\text { Kinerja } \\
\text { RAM/Memori (\%) }\end{array}$ \\
\hline 1 & 1 user & 1 unit & 15 & 62 \\
\hline 2 & 2 user & 2 unit & 28 & 69 \\
\hline 3 & 3 user & 3 unit & 72 & 83 \\
\hline 4 & 4 user & 4 unit & 100 & 86 \\
\hline
\end{tabular}

\subsection{Analisa PC Cloning}

Dalam tahap analisa PC Cloning terdapat dua tahapan analisa :

1. Analisa Konsumsi Listrik

2. Analisa Performa PC Cloning.

\subsubsection{Analisa Konsumsi Listrik}

Analisa konsumsi listrik dilakukan dengan melihat konsumsi daya apakah terjadi penghematan konsumsi listrik, kemudian membandingkan data yang didapat antara PC tanpa Cloning dengan PC Cloning ditinjau dari banyaknya user didapat perbandinga sebagai berikut :

\section{Mode stanby}

Dari data yang telah dihasilkan pada tabel 4.1 dapat dibandingkan konsumsi listrik antara komputer tanpa PC Cloning dengan komputer yang telah menggunakan PC Cloning terhadap jumlah user pada mode stanby seperti yang yang terlihat pada grafik dibawah ini :

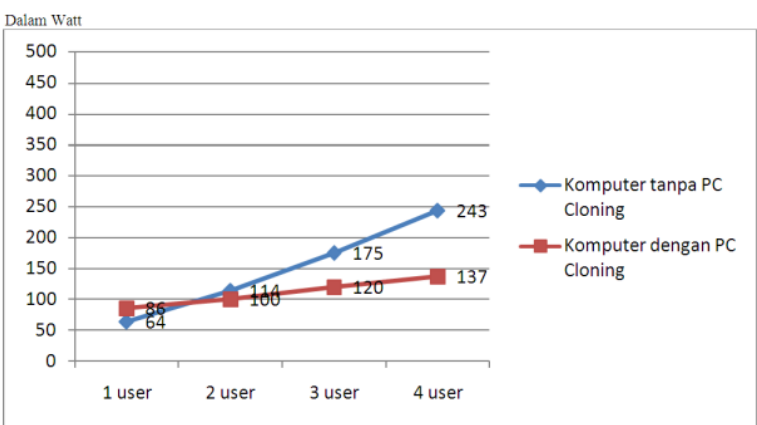

Gambar 4.1. Grafik Perbandingan Konsumsi Listrik Komputer Tanpa PC Cloning dengan Komputer Menggunakan PC Cloning Mode Stanby.

\section{Mode Aktif}

Dari data yang telah dihasilkan pada tabel 4.2 dapat dibandingkan konsumsi listrik antara komputer tanpa PC Cloning dengan komputer yang telah menggunakan PC Cloning terhadap jumlah user pada mode aktif seperti yang yang terlihat pada grafik dibawah ini :

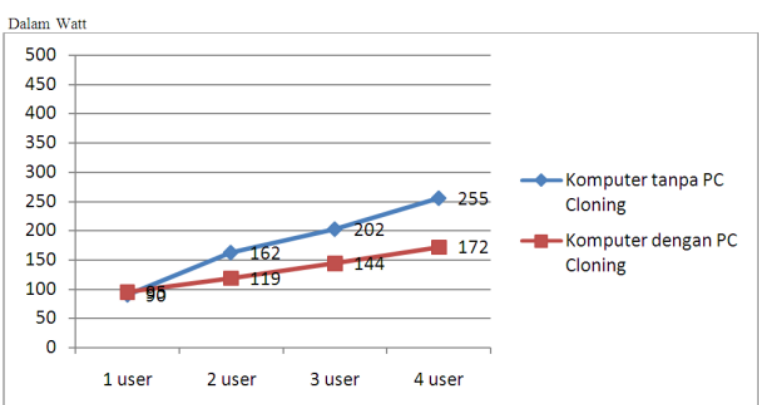

Gambar 4.2. Grafik Perbandingan Konsumsi Listrik Dari Komputer Tanpa PC Cloning Dengan Komputer Menggunakan PC Cloning Mode Aktif.

\section{2 .2. Analisa Performa PC Cloning}

Analisa performa PC Cloning dilakukan dengan cara melihat kerja Processor dan memeri komputer dalam menjalankan aplikasi yang terdiri dari tiga pengelompokan yaitu aplikasi kantor, aplikasi multimedia dan aplikasi grafis dengan menggunakan aplikasi task manager, serta terbagi menjadi 2 mode pengaplikasian yaitu mode stanby dan mode aktif. Kemudian membandingkan performa CPU dan memori dalam menjalankan aplikasi terhadap jumlah user dengan mode stanby dan mode aktif.

1. Microsoft office word 2007.

Dari data yang telah dihasilkan pengujian performa PC Cloningpada table 4.4 dalam menjalankan aplikasi Microsoft Office Word 2007 dapat dibandingkan performa CPU terhadap jumlah user dengan mode stanby dan mode aktif. 


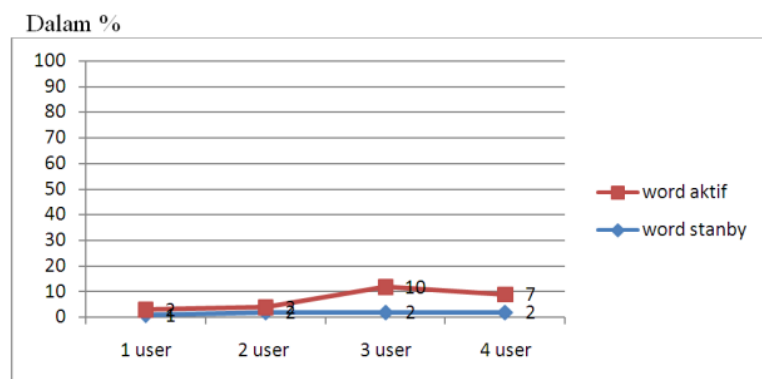

Gambar 4.3. Grafik Perbandingan Performa CPU dari Aplikasi Microsoft Office Word 2007

Terhadap Jumlah User dengan Mode Stanby dan Mode Aktif.

Kemudian pada memori atau RAM yang terpakai dari data yang telah dihasilkan pada pengujian performa PC Cloning dalam menjalankan aplikasi Microsoft Office Word 2007 dapat dibandingkan pemakaian memori terhadap jumlah user dengan mode stanby dan mode aktif pada grafik berikut :

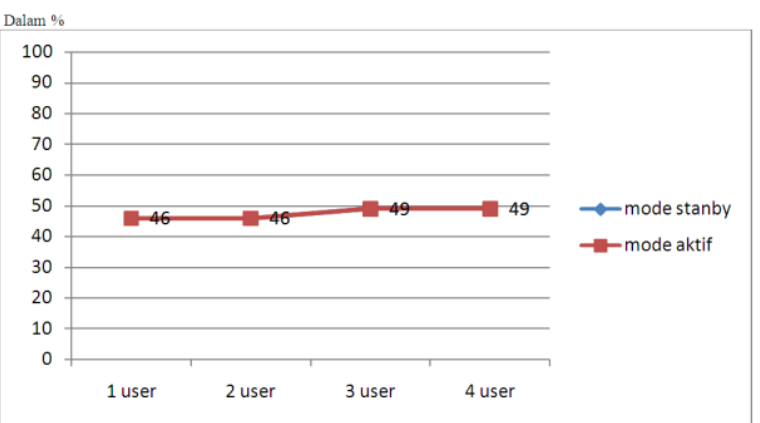

Gambar 4.4. Grafik Perbandingan Pemakaian memori dari Aplikasi Microsoft Office Word 2007 Terhadap Jumlah User Dengan Mode Stanby dan Mode Aktif.

\section{Mondo Marble.}

Dari data yang telah dihasilkan pengujian performa PC Cloning pada table 4.5 dalam menjalankan aplikasi Mondo Marble dapat dibandingkan performa CPU dan RAM terhadap jumlah user dengan mode mode aktif.

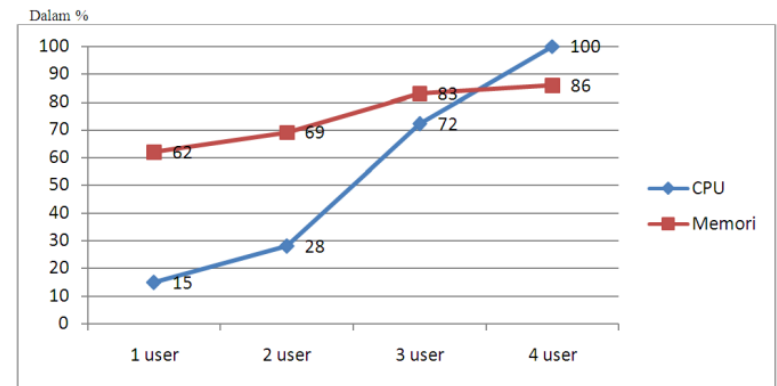

Gambar 4.4. Grafik Perbandingan Pemakaian memori dari Aplikasi Mondo Marble Terhadap Jumlah User dengan Mode Aktif.
Jika dilihat dari data yang telah dihasilkan dari pengujian performa dan analisa secara keseluruhan pada PC Cloning dalam menjalankan aplikasi kantor, aplikasi multimedia dan aplikasi grafis yang didasari oleh batasan pemakaian CPU sebesar $80 \%$. Maka dapat disimpulkan bahwa pemakaian ideal jumlah user secara keseluruhan yang dapat ditangani PC Cloning dalam menjalankan aplikasi adalah berjumlah 3 user saja mengingat keterbatasan dari spesifikasi hardware PC Cloning.

\section{Simpulan}

Berdasarkan hasil dan pembahasan dari penelitian ini dapat ditarik beberapa kesimpulan diantaranya:

1. PC Cloning berhasil diterapkan untuk pemakaian 4 user menggunakan satu PC.

2. Penghematan konsumsi daya berkisar antara $12,2 \%$ sampai $43,6 \%$, semakin banyak komputer yang di cloning konsumsi daya semakin rendah.

3. Performa kinerja processor PC Cloning lebih rendah dibandingkan dengan PC tanpa Cloning tetapi kinerja Processor masih mampu menangani 4 user yaitu dibawah $80 \%$ dan penggunaan memori dibawah $90 \%$

4. Program multimedia seperti Adobe Flash CS6 dan game Mondo Marble tidak direkomendasikan untuk PC Cloning 4 user jika menggunakan Prosessor Intel Core i3-2120.

5. Komputer dengan spesifikasi Prosessor Intel Core i3-2120 dan memori 4 GB idealnya digunakan sebanyak 3 user.

\section{Daftar Pustaka}

[1] Fitriyatur R, Mimin., Penerapan Aplikasi Pc Cloning Berbasis Winconnect Menggunakan Windows Xp Sebagai Server dan Windows 2000 Sebagai Client pada Laboratorium Komputer di Unim. Jurnal ORASI. Universitas Islam Majapahit. Mojo kerto. 2012. Page 2.

[2] Pratama, Rizky., Analisis Performansi Winconnect dengan Betwin pada jaringan PC Cloning. Jurnal Tugas Akhir. Politeknik Telkom Bandung. Bandung. 2011. Page 3. 
[3] Purba, Sondang., 2009. Implementasi Jaringan PC Cloning Dengan Windows 2003 Menggunakan Aplikasi Citrix Metaframe XP. Laporan Tugas Akhir. Universitas Sumatera Utara. Medan.

[4] Microsoft Team, 2011. Windows Multipoint Server 2011.

(http://www.microsoft.com/indonesia/wi ndows/multipoint/default.aspx, diakses pada 14 maret 2013, pukul 14.30 WIB).

[5] Microsoft Team, 2013. MultiPoint Server Stations.(http://technet.microsoft.com/idid/library/jij916411.aspx, diakses pada 14 Maret 2013, pukul 15.00 WIB). 